\title{
Retraction Note to: Desert \\ Halophytes: Alleviating \\ the Pressure on the Scarce \\ Resources of Arable Soil \\ and Freshwater
}

\author{
Amram Eshel, Chingiz Alekperov, Israel Oren, \\ Tamar Eilam, and Aviah Zilberstein
}

\section{Retraction Note to: \\ Chapter "Desert Halophytes: Alleviating the Pressure on the \\ Scarce Resources of Arable Soil and Freshwater" in: B. Gul et al. (eds.), \\ Sabkha Ecosystems, Tasks for Vegetation Science VI, https://doi.org/10.1007/978-3-030-04417-6_6}

The authors have retracted this chapter [1] because it has been previously published as a journal article by the same authors [2]. This chapter is therefore redundant. All authors agree with this retraction.

[1] Eshel A., Alekperov C., Oren I., Eilam T., Zilberstein A. (2019) Desert Halophytes: Alleviating the Pressure on the Scarce Resources of Arable Soil and Freshwater. In: Gul B., Böer B., Khan M., Clüsener-Godt M., Hameed A. (eds) Sabkha Ecosystems. Tasks for Vegetation Science, vol 49. Springer, Cham.

[2] Amram Eshel, Israel Oren, Chingiz Alekperov, Tamar Eilam, Aviah Zilberstein (Israel) Biomass Production by Desert Halophytes: Alleviating the Pressure on the Scarce Resources of Arable Soil and Fresh Water In: Muscolo A, Flowers TJ (Eds) Proceedings of the European COST action FA0901. The European Journal of Plant Science and Biotechnology 20115 (Special Issue 2), 48-53.

The retracted online version of this chapter can be found at https://doi.org/10.1007/978-3-030-04417-6_6 